Research Article

\title{
Structural and Magnetic Properties of Mn Doped $\mathrm{BiFeO}_{3}$ Nanomaterials
}

\author{
V. Srinivas, ${ }^{1}$ A. T. Raghavender, ${ }^{2}$ and K. Vijaya Kumar ${ }^{3}$ \\ ${ }^{1}$ Department of Physics, Government Institute of Electronics, Secunderabad 500026, India \\ ${ }^{2}$ Department of Electronics and Communication Engineering, Nishitha College of Engineering and Technology, \\ Hyderabad 509215, India \\ ${ }^{3}$ Department of Physics, JNTUH College of Engineering Jagtial, Nachupally (Kondagattu), Karimnagar 505 501, India
}

Correspondence should be addressed to K. Vijaya Kumar; kvkphd@gmail.com

Received 18 October 2015; Accepted 22 February 2016

Academic Editor: Ali Hussain Reshak

Copyright (C) 2016 V. Srinivas et al. This is an open access article distributed under the Creative Commons Attribution License, which permits unrestricted use, distribution, and reproduction in any medium, provided the original work is properly cited.

\begin{abstract}
Nanocrystalline $\mathrm{Bi}_{1-x} \mathrm{Mn}_{x} \mathrm{FeO}_{3}(0 \leq x \leq 0.3)$ materials were synthesized using sol-gel technique. The structural and magnetic properties were investigated in detail. Rietveld analysis from XRD revealed the structural formation of $\mathrm{BiFeO}_{3}$. As the $\mathrm{Mn}$ doping concentration was increased, the structure of $\mathrm{BiFeO}_{3}$ changed from rhombohedral to tetragonal. All the $\mathrm{M}-\mathrm{H}$ loops showed the ferromagnetic behavior in the prepared samples. Magnetization was observed to enhance as the Mn doping concentration was increased. The enhanced magnetization may be due to the collapse of the space modulated spin structure as observed from the structural changes.
\end{abstract}

\section{Introduction}

$\mathrm{BiFeO}_{3}(\mathrm{BFO})$ is an interesting material due to the coexistence of G-type antiferromagnetic (AFM) structure having Néel temperature around $640 \mathrm{~K}$ and ferroelectric polarization with Curie temperature around $1000 \mathrm{~K}[1,2]$. BFO is considered to be superior candidate for the next generation devices such as spintronics, piezoelectric sensors, optoelectronic devices, nonvolatile memories, and high density microactuators $[3,4]$. The spontaneous magnetization in $\mathrm{BFO}$ could be induced by changing $\mathrm{Fe}-\mathrm{O}-\mathrm{Fe}$ bond angle or by the statistical octahedral distribution of $\mathrm{Fe}[5,6]$. Room temperature ferromagnetic properties of rare earth and transition metal ions doped $\mathrm{BFO}$ materials were observed by several researchers. The enhanced magnetization was observed in $\mathrm{BFO}$ due to the divalent, trivalent, and rare earth ions on $\mathrm{Fe}$ site $[7,8]$. Literature suggests that the superexchange interaction within $\mathrm{Fe}^{3+}-\mathrm{O}-\mathrm{Fe}^{2+}$ gives rise to a finite value of magnetization in $\mathrm{BFO}$ [9]. The enhanced magnetization in $\mathrm{Mn}$ and Ho doped $\mathrm{BFO}$ thin films prepared by chemical solution deposition was due to the collapse of space modulated spin structure by the structural transition [10]. The magnetic ordering in BFO is G-type antiferromagnetic; the contribution of the antiferromagnetic sublattices could lead to weak ferromagnetism [11]. Doping of trivalent, divalent, and rare earth elements in BFO was observed to enhance the magnetization by suppressing the cycloid spin structure and reducing the leakage current density and enhancing the multiferroic properties [12-16]. When $\mathrm{Mn}$ is substituted for $\mathrm{Fe}$ site, ferroelectric properties were observed to improve [17]. It was observed that BFO shows weak magnetization and poor polarization due to the spiral spin structure and leakage problem $[18,19]$. The secondary phases and oxygen vacancies in BFO may also affect the magnetic and electrical properties $[1,20]$. The magnetic properties of BFO are also related to the local spin structure of $\mathrm{FeO}_{6}$ octahedron [18]. Among all the elements $\mathrm{Mn}$ doped $\mathrm{BFO}$ was observed to contribute to enhanced magnetization [21, 22]. Bulk BFO crystallizes in a rhombohedral distorted perovskite structure $R 3 c$ space group. Partially $d$ orbital of Fe ions leads to Gtype antiferromagnetic structure [23-25]. BFO multiferroic materials in nanofilm, bulk film, and thin film forms have been extensively investigated during the last decade. Since $\mathrm{BFO}$ materials are having interesting properties, therefore, in the present work, we aimed to present their structural and magnetic properties in detail. 


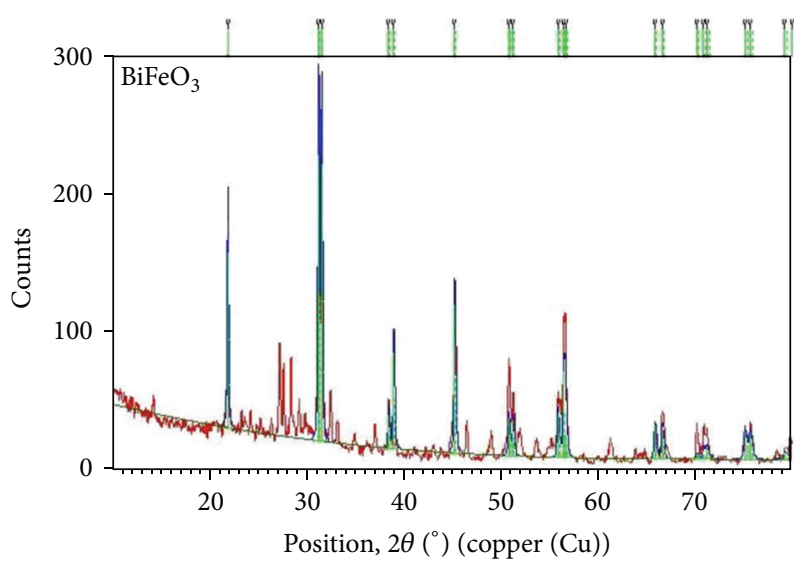

20372-ICSD $100.0 \%$

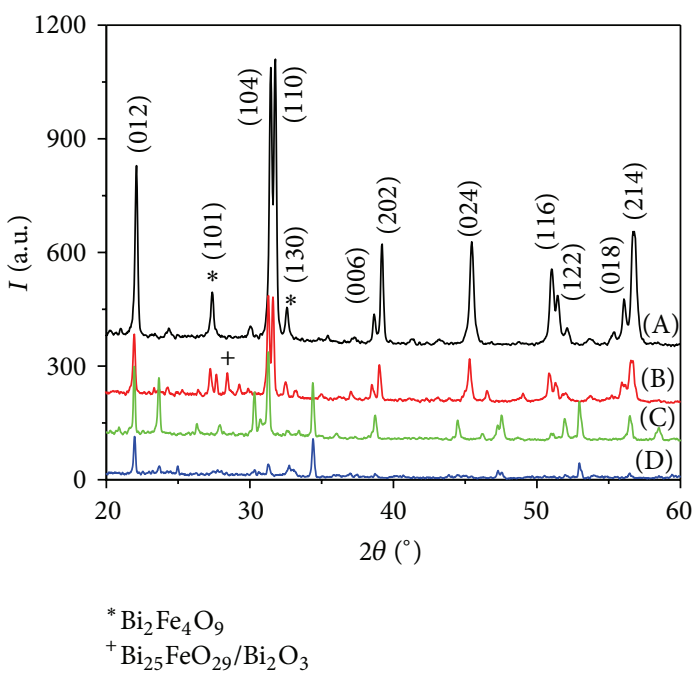

(b)

Figure 1: (a) Rietveld analysis of $\mathrm{BiFeO}_{3}$ sample. (b) X-ray diffraction patterns of $\mathrm{Bi}_{1-x} \mathrm{Mn}_{x} \mathrm{FeO}_{3}$ : (a) $x=0.0$, (b) $x=0.1$, (c) $x=0.2$, and (d) $x=0.3$.

\section{Experimental}

Mn doped BFO was synthesized using sol-gel method $[7,8,26]$. The A.R Grade citric acid $\left(\mathrm{C}_{6} \mathrm{H}_{8} \mathrm{O}_{7} \cdot \mathrm{H}_{2} \mathrm{O}\right)$, bismuth nitrate $\left(\mathrm{Bi}\left(\mathrm{NO}_{3}\right)_{3} \cdot 5 \mathrm{H}_{2} \mathrm{O}\right)$, manganese nitrate $\left(\mathrm{Mn}\left(\mathrm{NO}_{3}\right)_{3} \cdot 4 \mathrm{H}_{2} \mathrm{O}\right)$, and ferric nitrate $\left(\mathrm{Fe}\left(\mathrm{NO}_{3}\right)_{3} \cdot 9 \mathrm{H}_{2} \mathrm{O}\right)$ $(\geq 99 \%)$ were used as starting materials. During synthesis, an excess of $\approx 5 \mathrm{wt} . \%$ Bi was added to compensate bismuth oxide loss during the thermal treatment. Without this additional bismuth addition, the pure phase of BFO could not be obtained. The entire synthesis process is described elsewhere [26]. The as-prepared powder samples were heat treated at temperature of $600^{\circ} \mathrm{C}$. The X-ray diffraction of the ferrite powders was carried using a Philips PW 1820 powder diffractometer with $\mathrm{CuK} \alpha$ graphite monochromated radiation, operating at $40 \mathrm{kV}$ and $30 \mathrm{~mA}$, with solar slits and divergent and receiving slits of $0.2 \mathrm{~mm}$. The diffracted intensity was registered in the angular range $8^{\circ} \leq 2 \theta \leq$ $80^{\circ}$, with a step size of $0.02^{\circ}(2 \theta)$. The micrographs of all samples were taken on FEI Quanta FEG 200 High Resolution Scanning Electron Microscope. Room temperature magnetic properties were investigated using Lakeshore's (USA) vibrating sample magnetometer (VSM 7410).

\section{Results and Discussions}

Figure 1(a) shows Rietveld analysis for $\mathrm{BiFeO}_{3}$ sample. All the XRD peaks correspond to $\mathrm{BiFeO}_{3}$ structure. Apart from the main $\mathrm{BiFeO}_{3}$ peaks few minor peaks belonging to $\mathrm{Bi}_{2} \mathrm{Fe}_{4} \mathrm{O}_{9} / \mathrm{Bi}_{25} \mathrm{FeO}_{29} / \mathrm{Bi}_{2} \mathrm{O}_{3}$ are visible in the $2 \theta^{\circ}$ range between 25 and 30. It is reported most often that $\mathrm{BiFeO}_{3}$ is accompanied by secondary phases such as $\mathrm{Bi}_{2} \mathrm{Fe}_{4} \mathrm{O}_{9}$ and $\mathrm{Bi}_{25} \mathrm{FeO}_{29}$ [27-29]. The impurity phases in the XRD patterns could be attributed to the volatilization of $\mathrm{Bi}^{3+}$ ions which resulted due to excess addition of $\mathrm{Bi}$. The high vapour pressure of $\mathrm{Bi}$ atoms tends easy evaporation of $\mathrm{Bi}^{3+}$ ions during synthesis conditions, such as drying and annealing conditions. Therefore, for $\mathrm{Mn}$ and $\mathrm{BFO}$ synthesis, we have used excess $\mathrm{Bi}^{3+}$ ions. Without this additional bismuth addition, the pure phase of $\mathrm{BFO}$ could not be obtained. Berbenni et al. [29] showed that if $\mathrm{BFO}$ is annealed at temperatures $\geq 750^{\circ} \mathrm{C}$, the secondary phases such as $\mathrm{BiO}_{3}, \mathrm{Fe}_{2} \mathrm{O}_{3}$, and $\mathrm{Bi}_{2} \mathrm{Fe}_{4} \mathrm{O}_{9}$ will disappear. It seems that higher annealing temperature increases the intensity of characteristic BFO peaks and reduces the intensity of secondary phases but it may not be possible to avoid the secondary phases even though the samples were annealed at $800^{\circ} \mathrm{C}$ [29]. When we annealed $\mathrm{BFO}$ powders at temperatures $\geq 750^{\circ} \mathrm{C}$, the $\mathrm{BFO}$ powder melted and stuck to the crucible. For this reason, we have cho$\operatorname{sen} 600^{\circ} \mathrm{C}$ as the final annealing temperature for our samples.

From Figure 1(b), it is clearly observed that, for $x<$ 0.2 , the diffraction can be indexed to a rhombohedral $(R 3 c)$ structure, whereas for $x=0.2$ it is tetragonal $(P 4 \mathrm{~mm})$ phase. Similar kind of results was observed for $(1-$ $x) \mathrm{BiFeO}_{3-x} \mathrm{LaMnO}_{3}$ synthesized by sol-gel method [30]. The XRD diffraction peaks for all the samples were similar to those published in the literature. The diffraction peak at $2 \theta$, $22.5^{\circ}$ (012) and diffraction peak around $32^{\circ}$ (104) and (110) are indexed for rhombohedral structure. With the increase in Mn concentration to $x=0.1$ the diffraction at $46^{\circ}$ splits into two peaks (002) and (200) as a characteristic peak for tetragonal $(P 4 \mathrm{~mm})$ space group. The rhombohedral $(R 3 \mathrm{c})$ structure was observed for pure BFO and was considered as the distortion from cubic perovskite pmsm structure [31]. When the pmsm and $R 3 c$ crystal structures were present in samples simultaneously, they were expected to show both weak ferromagnetic and ferroelectric properties [31].

Figure 2 shows the SEM micrographs for all the samples. SEM analysis showed the average grain size around $200 \mathrm{~nm}$. There was no significant change in the grain size with the increase in $\mathrm{Mn}$ doping concentration. The magnetic hysteresis loops of $\mathrm{Bi}_{1-x} \mathrm{Mn}_{x} \mathrm{FeO}_{3}(0 \leq x \leq 0.3)$ samples are shown 


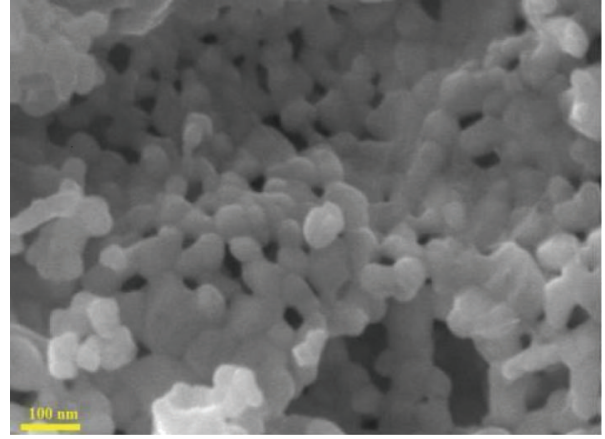

(a)

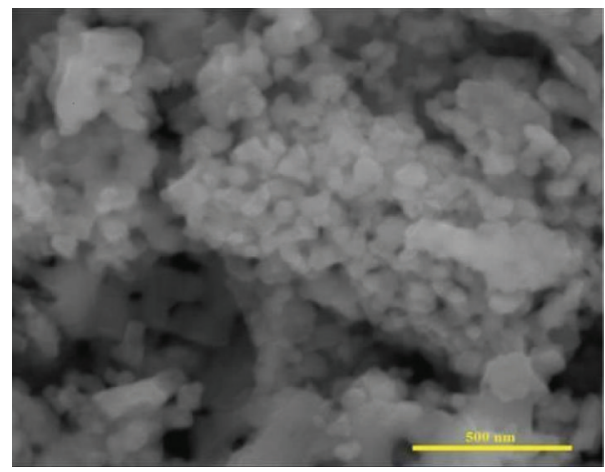

(c)

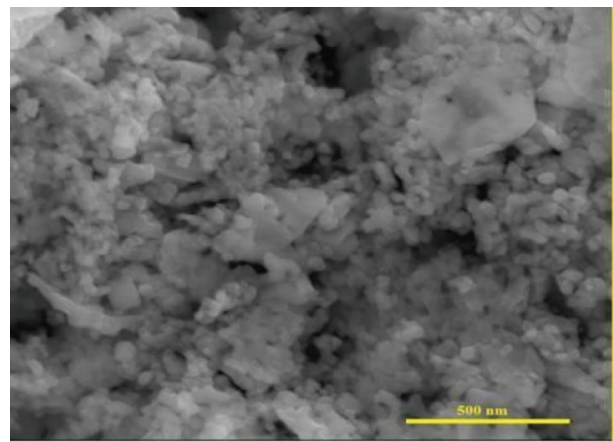

(b)

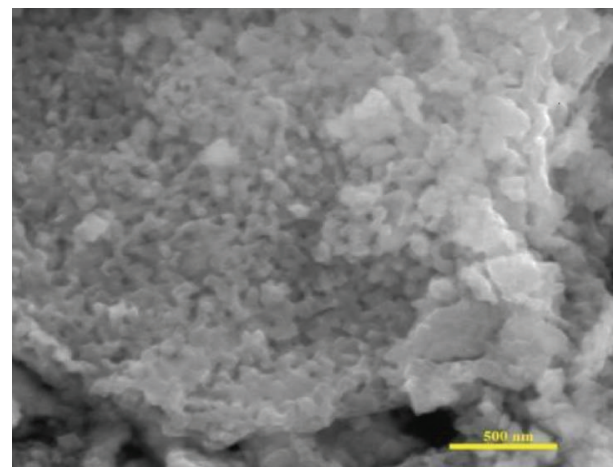

(d)

Figure 2: SEM micrographs of $\mathrm{Bi}_{1-x} \mathrm{Mn}_{x} \mathrm{FeO}_{3}$ : (a) $x=0.0$, (b) $x=0.1$, (c) $x=0.2$, and (d) $x=0.3$.

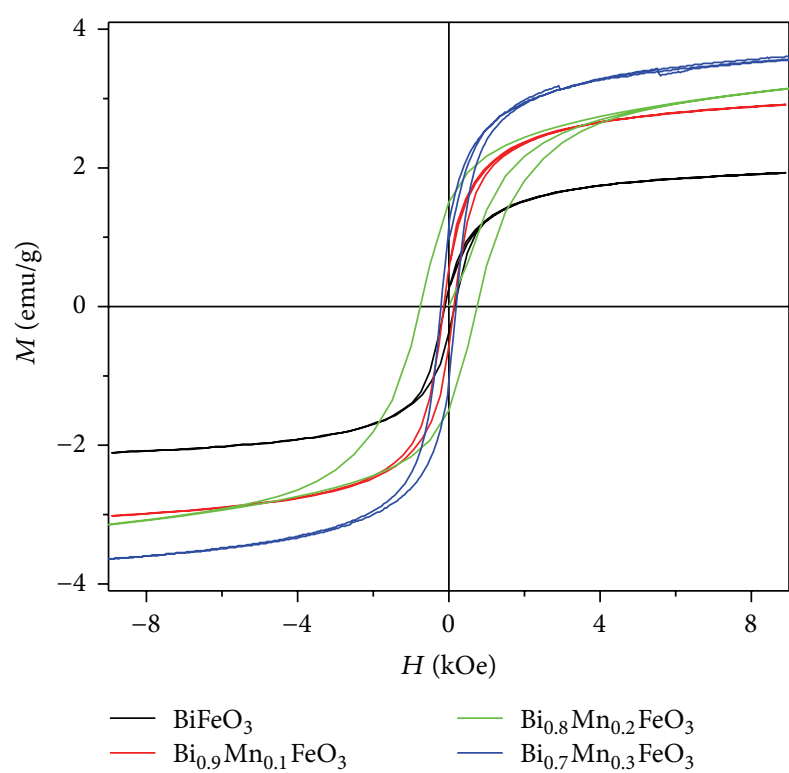

Figure 3: Magnetic hysteresis loops of $\mathrm{Bi}_{1-x} \mathrm{Mn}_{x} \mathrm{FeO}_{3}$ samples measured at room temperature.

in Figure 3. All the samples show unsaturated magnetization. The highest magnetization was observed for the composition $x=0.3$. Similar kinds of results were observed for $x=0.35$ for $(1-x)$ BFOBCZT ceramics [23]. Pure BFO is observed to be antiferromagnetic with G-type spin ordering below Néel's temperature. As there was no significant change in the BMFO grain size with doping concentration (see Figure 2), it can be said that the enhancement of magnetization may not be attributed to the dependency of size on the doping concentration. Similar kinds of results were observed for Mn doped BFO powder samples [18]. The weak ferromagnetism in BFO powder samples was observed to depend not only on the DM interactions but also on the single-ion anisotropy [31, 32]. It is well known that BFO is G-type antiferromagnet and each $\mathrm{Fe}^{3+}$ spin is surrounded by six canted antiparallel spins on the nearest Fe neighbors which allow net magnetic moment $[8,9]$. Except for sample $x=0.2$ all other samples showed very small remanent magnetization; the exact reason for this kind of behavior is not known. The observed hysteresis of all the samples without saturation point was explained due to the persistence of the uncompensated antiferromagnetism in the samples [23]. As the Mn doping concentration was increased, the magnetization was observed to increase. Mn substitution induced the structural phase change from $R 3 \mathrm{c}$ to $P 4 \mathrm{~mm}$ and this results in the destruction of spin cycloid structure and thus the homogeneous structure was formed. Wu et al. [30] reported the enhanced magnetization due to $\mathrm{Mn}$ and $\mathrm{La}$ codoping. However, the observed magnetization value for our samples was small compared to those in literature. This might be due to several factors such as synthesis technique, synthesis conditions, annealing conditions, and temperature. The enhanced magnetization with further substitution of $\mathrm{Fe}^{3+}$ ions with $\mathrm{Mn}^{3+}\left(\mathrm{d}^{4}\right)$ ions could break the balance within antiparallel sublattice magnetization due to the Jahn-Teller 
distortion of $\mathrm{MnO}_{6}$ octahedron [30, 33]. For small doping concentration of Mn, Jahn-Teller distortion would enhance and may affect the DM interactions which in turn enhance the weak ferromagnetism $[20,23,30-32,34]$. It was observed that ferromagnetism in Mn doped BFO might be due to induced defects created by excess $\mathrm{Bi}$ in the interstitial region of the BFO lattice [32].

The magnetic interactions of $\mathrm{BFO}$ can be modified by the substitution of different elements in BFO [30]. Several researchers have tried to improve the structural and magnetic properties of BFO by substituting transition metals [1,35-42]. Structural defects, control of grain size, or thickness of thin films can regulate the magnetic properties of thin films [43]. Introducing defects like oxygen vacancies during synthesis in BFO powders or thin films also induces ferromagnetism [44]. For multiferroic materials, they are required to have both ferroelectric and ferromagnetic properties. As observed from our results, these samples showed both rhombohedral $(R 3 c)$ and tetragonal $(P 4 \mathrm{~mm})$ structures; therefore, these materials could be suitable for ferroelectric materials.

\section{Conclusions}

Mn doped BFO nanopowders were successfully synthesized using sol-gel method. Pure BFO showed rhombohedral structure. As the Mn doping content was increased, the structure of the sample changed from rhombohedral to tetragonal structure. Grain size did not show any considerable change with increasing doping concentration. The magnetization was observed to enhance as the doping content was increased due to Jahn-Teller distortion. With the appearance of rhombohedral $(R 3 c)$ and tetragonal $(P 4 \mathrm{~mm})$ structures, these materials could be suitable candidate for ferroelectric materials.

\section{Competing Interests}

The authors declare that there are no competing interests regarding the publication of this paper.

\section{Acknowledgments}

The authors are grateful to sophisticated analytical instrument facility (SAIF), Indian Institute of Technology (IIT), Madras, India, for providing the experimental facilities. K. Vijaya Kumar is thankful to Professor N. V. Ramana, Principal, JNTUH CEJ, Nachupally (Kondagattu), Karimnagar District.

\section{References}

[1] J. Wang, J. B. Neaton, H. Zheng et al., "Epitaxial BiFeO3 multiferroic thin film heterostructures," Science, vol. 299, no. 5613, pp. 1719-1722, 2003.

[2] H. J. Feng, M. Wang, F. Liu, B. Duan, J. Tiam, and X. Guo, "Enhanced optical properties and the origin of carrier transport in $\mathrm{BiFeO}_{3} / \mathrm{TiO}_{2}$ heterostructures with $109^{\circ}$ domain walls," Journal of Alloys and Compounds, vol. 628, pp. 311-316, 2015.
[3] H. Uchida, R. Ueno, H. Funakubo, and S. Koda, "Crystal structure and ferroelectric properties of rare-earth substituted $\mathrm{BiFeO}_{3}$ thin films," Journal of Applied Physics, vol. 100, no. 1, Article ID 014106, 2006.

[4] C. M. Raghavan, J. W. Kim, and S. S. Kim, "Effects of Ho and Ti doping on structural and electrical properties of $\mathrm{BiFeO}_{3}$ thin films," Journal of the American Ceramic Society, vol. 97, no. 1, pp. 235-240, 2014.

[5] D. Kothari, V. Raghavendra Reddy, A. Gupta et al., "Study of the effect of Mn doping on the $\mathrm{BiFeO}_{3}$ system," Journal of Physics: Condensed Matter, vol. 19, no. 13, Article ID 136202, 2007.

[6] W. Prellier, M. P. Singh, and P. Murugavel, "The single-phase multiferroic oxides: from bulk to thin film," Journal of Physics: Condensed Matter, vol. 17, no. 30, pp. R803-R832, 2005.

[7] T.-Y. Kim, N. H. Hong, T. Sugawara, A. T. Raghavender, and M. Kurisu, "Room temperature ferromagnetism with large magnetic moment at low field in rare-earth-doped $\mathrm{BiFeO}_{3}$ thin films," Journal of Physics: Condensed Matter, vol. 25, no. 20, Article ID 206003, 2013.

[8] A. T. Raghavender, N. H. Hong, C. Park, M.-H. Jung, K. J. Lee, and D. Lee, "Thickness dependent magnetic properties of $\mathrm{BiFeO}_{3}$ thin films prepared by pulsed laser deposition," Materials Letters, vol. 65, no. 17-18, pp. 2786-2788, 2011.

[9] N. H. Hong, N. T. Huong, T.-Y. Kim, S. Goumri-Said, and M. B. Kanoun, "Tuning magnetic properties of $\mathrm{BiFeO}_{3}$ thin films by controlling rare-earth doping: experimental and first-principles studies," The Journal of Physical Chemistry C, vol. 119, no. 25, pp. 14351-14357, 2015.

[10] W. Ye, G. Tan, G. Dong, H. Ren, and A. Xia, "Improved multiferroic properties in $(\mathrm{Ho}, \mathrm{Mn})$ co-doped $\mathrm{BiFeO}_{3}$ thin films prepared by chemical solution deposition," Ceramics International, vol. 41, no. 3, pp. 4668-4674, 2015.

[11] Y. Wang and C.-W. Nan, "Effect of Tb doping on electric and magnetic behavior of $\mathrm{BiFeO}_{3}$ thin films," Journal of Applied Physics, vol. 103, no. 2, Article ID 024103, 5 pages, 2008.

[12] G. D. Hu, X. Cheng, W. B. Wu, and C. H. Yang, "Effects of Gd substitution on structure and ferroelectric properties of $\mathrm{BiFeO}_{3}$ thin films prepared using metal organic decomposition," Applied Physics Letters, vol. 91, no. 23, Article ID 232909, 2007.

[13] T. D. Rao, T. Karthik, A. Srinivas, and S. Asthana, "Study of structural, magnetic and electrical properties on Ho-substituted $\mathrm{BiFeO}_{3}$," Solid State Communications, vol. 152, no. 23, pp. 20712077, 2012.

[14] C. M. Raghava, J. W. Kim, and S. S. Kim, "Structural and electrical properties of $\left(\mathrm{Bi}_{0.9} \mathrm{Dy}_{0.1}\right)\left(\mathrm{Fe}_{0.975} \mathrm{TM}_{0.025}\right) \mathrm{O}_{3 \pm \delta}(\mathrm{TM}=$ $\mathrm{Ni}^{2+}, \mathrm{Cr}^{3+}$ and $\left.\mathrm{Ti}^{4+}\right)$ thin films," Ceramics International, vol. 39, no. 6, pp. 6057-6062, 2013.

[15] P. Suresh and S. Srinath, "Effect of La substitution on structure and magnetic properties of sol-gel prepared $\mathrm{BiFeO}_{3}$," Journal of Applied Physics, vol. 113, no. 17, Article ID 17D920, 2013.

[16] S. K. Srivastav, N. S. Gajbhiye, and A. Banerjee, "Structural transformation and enhancement in magnetic properties of single-phase $\mathrm{Bi}_{1-x} \mathrm{Pr}_{x} \mathrm{FeO}_{3}$ nanoparticles," Journal of Applied Physics, vol. 113, no. 20, Article ID 203917, 2013.

[17] S. K. Singh and H. Ishiwara, "Room temperature ferroelectric properties of $\mathrm{Mn}$-substituted $\mathrm{BiFeO}_{3}$ thin films deposited on $\mathrm{Pt}$ electrodes using chemical solution deposition," Applied Physics Letters, vol. 88, no. 26, Article ID 262908, 2006.

[18] L. Chen, L. Zheng, Y. He, J. Zhang, Z. Mao, and X. Chen, "The local distortion and electronic behavior in $\mathrm{Mn}$ doped $\mathrm{BiFeO}_{3}$," Journal of Alloys and Compounds, vol. 633, pp. 216-219, 2015. 
[19] G. Catalan and J. F. F. Scott, "Physics and applications of bismuth ferrite," Advanced Materials, vol. 21, no. 24, pp. 2463-2485, 2009.

[20] C. Ederer and N. A. Spaldin, "Influence of strain and oxygen vacancies on the magnetoelectric properties of multiferroic bismuth ferrite," Physical Review B, vol. 71, no. 22, Article ID 224103, 2005.

[21] S. Chauhan, M. Kumar, S. Chhoker et al., "Multiferroic, magnetoelectric and optical properties of $\mathrm{Mn}$ doped $\mathrm{BiFeO}_{3}$ nanoparticles," Solid State Communications, vol. 152, no. 6, pp. 525-529, 2012.

[22] I. Sosnowska, W. Schafer, W. Kockelman, H. Andersen, and L. O. Troyanchuk, "Crystal structure and spiral magnetic ordering of $\mathrm{BiFeO}_{3}$ doped with manganese," Applied Physics A, vol. 74, supplement 1, pp. s1040-s1042, 2002.

[23] J. Yi, Y. Tian, L. Wei et al., "Structure, dielectric, ferroelectric, and magnetic properties of $(1-x) \mathrm{BiFeO}_{3-x}$ $\left(\mathrm{Ba}_{0.85} \mathrm{Ca}_{0.15}\right)\left(\mathrm{Zr}_{0.10} \mathrm{Ti}_{0.90}\right) \mathrm{O}_{3}$ ceramics," Materials Research Bulletin, vol. 66, pp. 132-139, 2015.

[24] W. Eerenstein, N. D. Mathur, and J. F. Scott, "Multiferroic and magnetoelectric materials," Nature, vol. 442, no. 7104, pp. 759$765,2006$.

[25] S.-W. Cheong and M. Mostovoy, "Multiferroics: a magnetic twist for ferroelectricity," Nature Materials, vol. 6, no. 1, pp. 13-20, 2007.

[26] A. T. Raghavender and N. H. Hong, "Effects of Mn doping on structural and magnetic properties of multiferroic $\mathrm{BiFeO}_{3}$," Journal of Magnetics, vol. 16, no. 1, pp. 19-22, 2011.

[27] I. Sosnowska, T. P. Neumaier, and E. Steichele, "Spiral magnetic ordering in bismuth ferrite," Journal of Physics C: Solid State Physics, vol. 15, no. 23, p. 4835, 1982.

[28] R. Palai, R. S. Katiyar, H. Schmid et al., " $\beta$ Phase and $\gamma-\beta$ metal-

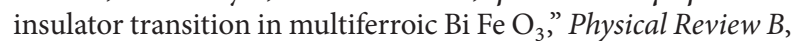
vol. 77, no. 1, Article ID 014110, 11 pages, 2008.

[29] V. Berbenni, C. Milanese, G. Bruni, A. Girella, and A. Marini, "Mechanical activation of the solid-phase reaction between bismuth citrate and iron(II) oxalate dihydrate to yield $\mathrm{BiFeO}_{3}$," Ceramics International, vol. 41, no. 5, pp. 7216-7220, 2015.

[30] J. Wu, N. Li, J. Xu, S. Zhou, Y. Jiang, and Z. Xie, "Synthesis, phase diagram and magnetic properties of $(1-x) \mathrm{BiFeO}_{3-x} \mathrm{LaMnO}_{3}$ solid solution," Journal of Alloys and Compounds, vol. 634, pp. 142-147, 2015.

[31] C. Ederer and N. A. Spaldin, "Weak ferromagnetism and magnetoelectric coupling in bismuth ferrite," Physical Review $B$, vol. 71, no. 6, Article ID 060401(R), 2005.

[32] S. K. Pradhan, J. Das, P. P. Rout et al., "Defect driven multiferroicity in $\mathrm{Gd}$ doped $\mathrm{BiFeO}_{3}$ at room temperature," Journal of Magnetism and Magnetic Materials, vol. 322, no. 22, pp. 3614$3622,2010$.

[33] G. Kartopu, A. Lahmar, and M. Es-Souni, "Observation of structural transitions and Jahn-Teller distortion in $\mathrm{LaMnO}_{3}$ doped $\mathrm{BiFeO}_{3}$ thin films," Applied Physics Letters, vol. 92, no. 15, Article ID 151910, 2008.

[34] L. S. Chen, Y. H. He, J. Zhang, Z. Q. Mao, Y. J. Zhao, and $\mathrm{X}$. Chen, "The oxygen octahedral distortion induced magnetic enhancement in multiferroic $\mathrm{Bi}_{1-x} \mathrm{Yb}_{x} \mathrm{Fe}_{0.95} \mathrm{Co}_{0.05} \mathrm{O}_{3}$ powders," Journal of Alloys and Compounds, vol. 604, pp. 327-330, 2014.

[35] N. Li, J. Wu, Y. Jiang, Z. Xie, L. Zheng, and Z.-G. Ye, "Structure and multiferroic properties of $\mathrm{Bi}_{(1-x)} \mathrm{Dy}_{x} \mathrm{Fe}_{0.90} \mathrm{Mg}_{0.05} \mathrm{Ti}_{0.05} \mathrm{O}_{3}$ solid solution," Journal of Applied Physics, vol. 113, no. 5, Article ID 054102, 2013.
[36] W.-M. Zhu, L. W. Su, Z.-G. Ye, and W. Ren, "Enhanced magnetization and polarization in chemically modified multiferroic $(1-x) \mathrm{BiFeO}_{3-x} \mathrm{DyFeO}_{3}$ solid solution," Applied Physics Letters, vol. 94, no. 14, Article ID 142908, 2009.

[37] Y.-J. Zhang, H.-G. Zhang, J.-H. Yin et al., "Structural and magnetic properties in $\mathrm{Bi}_{1-x} R_{x} \mathrm{FeO}_{3}(x=0-1, R=\mathrm{La}, \mathrm{Nd}, \mathrm{Sm}, \mathrm{Eu}$ and $\mathrm{Tb}$ ) polycrystalline ceramics," Journal of Magnetism and Magnetic Materials, vol. 322, no. 15, pp. 2251-2255, 2010.

[38] S. Y. Wang, X. Qiu, J. Gao et al., "Electrical reliability and leakage mechanisms in highly resistive multiferroic $\mathrm{La}_{0.1} \mathrm{Bi}_{0.9} \mathrm{FeO}_{3}$ ceramics," Applied Physics Letters, vol. 98, no. 15, Article ID 152902, 2011.

[39] V. A. Khomchenko, D. V. Karpinsky, A. L. Kholkin et al., "Rhombohedral-to-orthorhombic transition and multiferroic properties of Dy-substituted $\mathrm{BiFeO}_{3}$," Journal of Applied Physics, vol. 108, no. 7, Article ID 074109, 2010.

[40] F. Azough, R. Freer, M. Thrall, R. Cernik, F. Tuna, and D. Collison, "Microstructure and properties of Co-, Ni-, Zn-, Nband $\mathrm{W}$-modified multiferroic $\mathrm{BiFeO}_{3}$ ceramics," Journal of the European Ceramic Society, vol. 30, no. 3, pp. 727-736, 2010.

[41] V. A. Khomchenko, I. O. Troyanchuk, M. I. Kovetskaya, and J. A. Paixão, "Mn substitution-driven structural and magnetic phase evolution in $\mathrm{Bi}_{1-x} \mathrm{Sm}_{x} \mathrm{FeO}_{3}$ multiferroics," Journal of Applied Physics, vol. 111, no. 1, Article ID 014110, 2012.

[42] A. Ianculescu, F. P. Gheorghiu, P. Postolache, O. Oprea, and L. Mitoseriu, "The role of doping on the structural and functional properties of $\mathrm{BiFe}_{1-x} \mathrm{Mn}_{x} \mathrm{O}_{3}$ magnetoelectric ceramics," Journal of Alloys and Compounds, vol. 504, no. 2, pp. 420-426, 2010.

[43] T.-J. Park, G. C. Papaefthymiou, A. J. Viescas, A. R. Moodenbaugh, and S. S. Wong, "Size-dependent magnetic properties of single-crystalline multiferroic $\mathrm{BiFeO}_{3}$ nanoparticles," Nano Letters, vol. 7, no. 3, pp. 766-772, 2007.

[44] J. Wu, S. Mao, Z.-G. Ye, Z. Xie, and L. Zheng, "Roomtemperature ferromagnetic/ferroelectric $\mathrm{BiFeO}_{3}$ synthesized by a self-catalyzed fast reaction process," Journal of Materials Chemistry, vol. 20, pp. 6512-6516, 2010. 

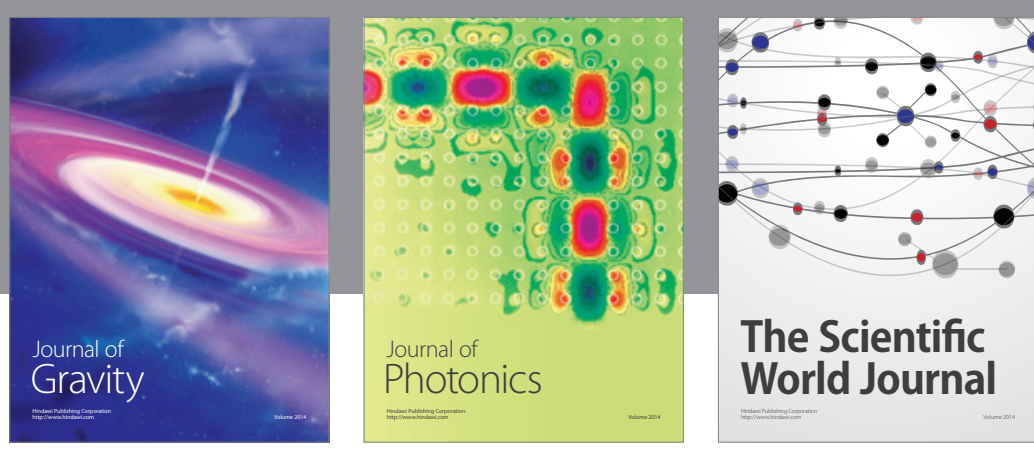

The Scientific World Journal
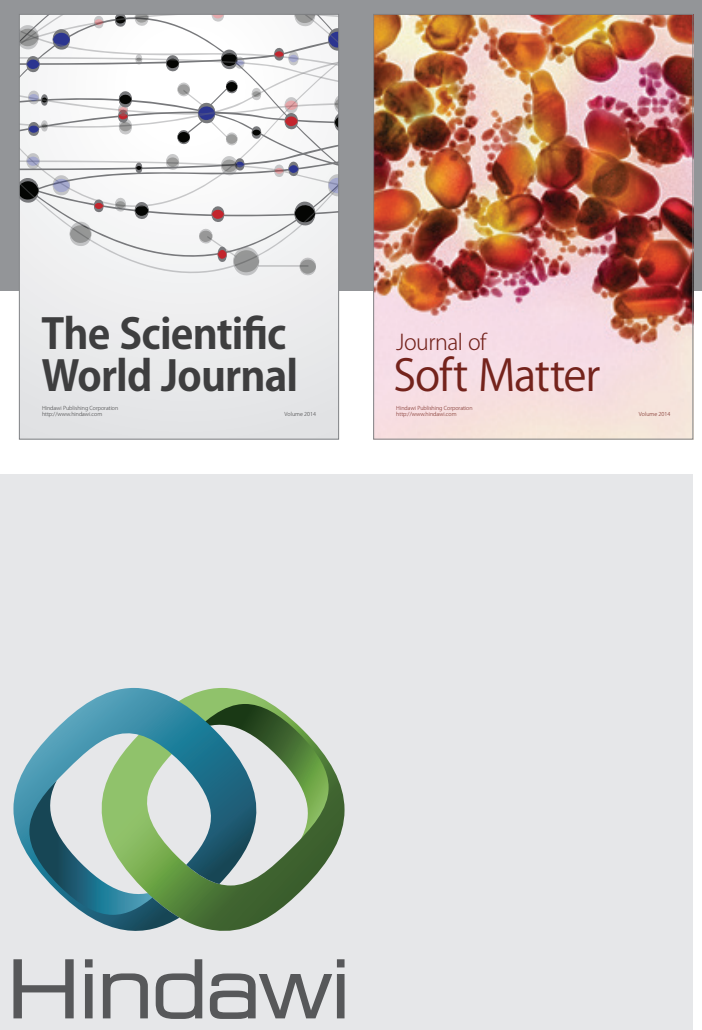

Submit your manuscripts at

http://www.hindawi.com

nternational Journal of

Statistical Mechanics
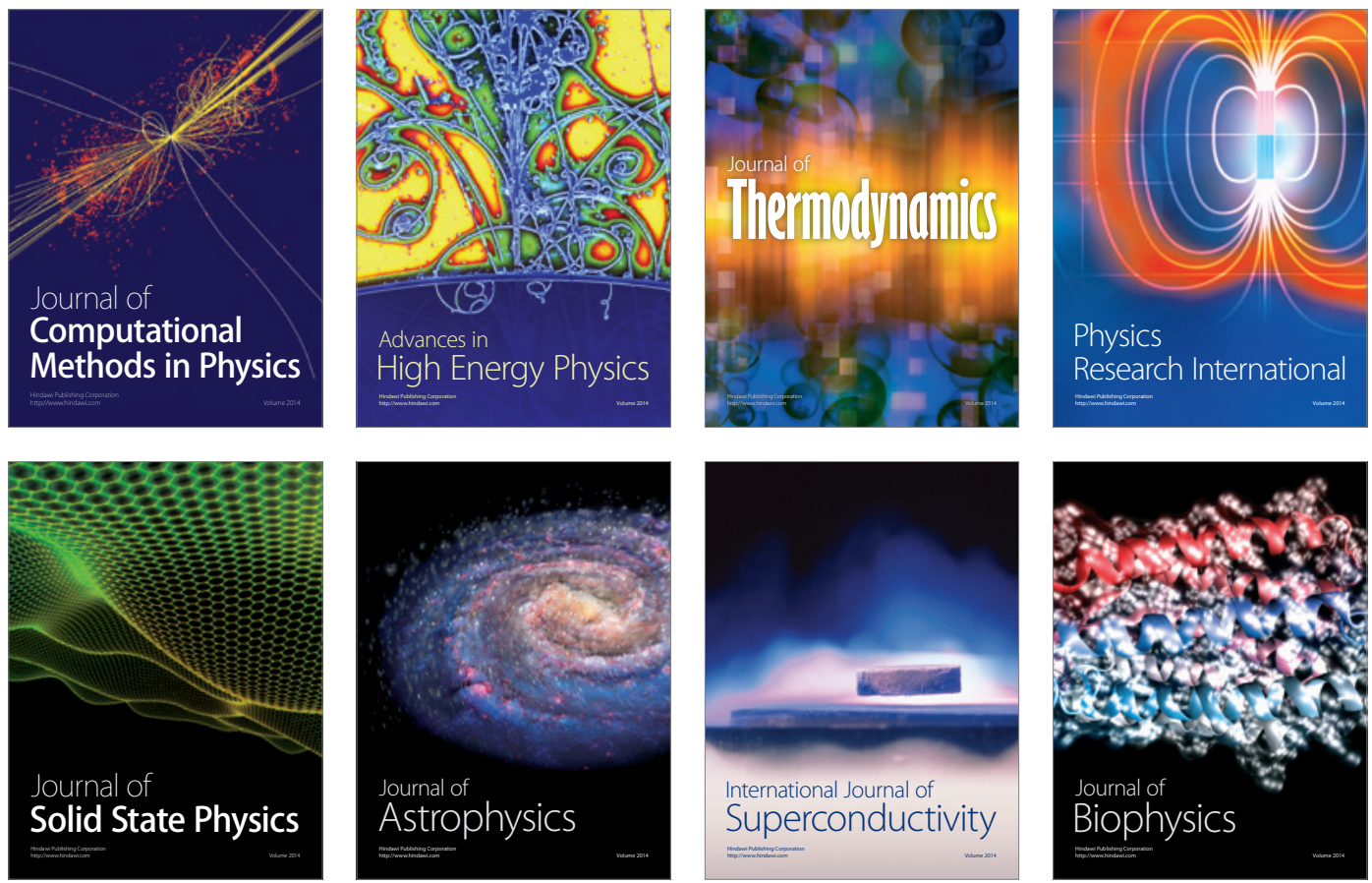
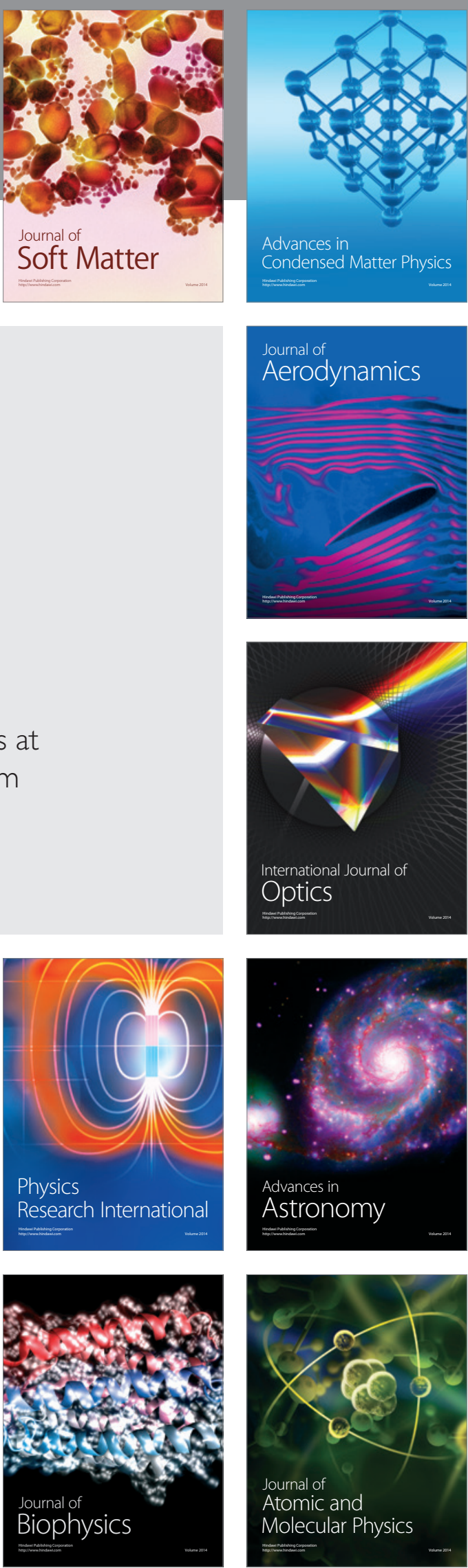